\title{
Influence of the Royal College of Radiologists' guidelines on hospital practice: a multicentre study
}

\author{
Royal College of Radiologists Working Party
}

College of Radiologists

coordinators

P Bourdillon

P R Camm

A Cohen

E R Davies

W P Ennis

K T Evans

M I Lavelle

J W Laws

M R McNulty

C J Roberts

G M Roberts

G Row

R Sutherland

JE Williams

Correspondence to:

Professor C J Roberts,

Department of

Epidemiology and

Community Medicine,

University of Wales College

of Medicine, Heath Park,

Cardiff CF4 4XN

BMF 1992;304:740-3
Members of the Royal

Working Party and local

P M Hacking

\section{Abstract}

Objective-To measure the effect on hospital radiology referral practice of introducing a strategy for change involving guidelines of good practice, monitoring, and peer review.

Design-Prospective data collection over a continuous 21-24 month period at each centre some time between January 1987 and December 1990.

Setting-Five district general hospitals and one district health authority.

Subjects-314663 inpatient discharges, deaths, and day cases and 1706781 outpatient attendances under the care of 722 consultants from 25 clinical specialties.

Main outcome measures - Number of referrals for $x$ ray examination per 100 inpatient discharges, deaths, and day cases and per 100 new outpatient attenders.

Results-Most doctors were prepared to accept standards of clinical practice set by peers and also the monitoring and review of their practice with respect to these standards by local colleagues. $18 \%$ of firms were identified before guidelines were instituted as having persistently high referral rates. Appreciable, and often dramatic reductions in referral rates for individual $x$ ray examinations were recorded by a substantial number of firms in every

Chest X-ray

\begin{tabular}{|c|c|c|}
\hline Circumstance & Guidelines & Exceptions \\
\hline Trauma to chest & $\begin{array}{l}\text { Routine demonstration of simple } \\
\text { rib fracture in minor trauma is } \\
\text { not recommended }\end{array}$ & $\begin{array}{l}\text { Severe trauma, particularly a } \\
\text { deceleration injury; suspected } \\
\text { multiple fractures; suspected } \\
\text { pleural or pulmonary injury. }\end{array}$ \\
\hline To screen for bronchial carcinoma & $\begin{array}{l}\text { Not recommended. } \\
\text { Periodic } x \text {-rays to detect early lung } \\
\text { cancer do not influence the prognosis }\end{array}$ & \\
\hline $\begin{array}{l}\text { To screen for pulmonary } \\
\text { tuberculosis }\end{array}$ & Not recommended routinely & $\begin{array}{l}\text { When the incidence of } \\
\text { pulmonary tuberculosis in the } \\
\text { patient's ethnic group may be } \\
\text { more than } 1: 1000 \text { and when } \\
\text { chest } x \text {-ray has not been } \\
\text { performed within the last six } \\
\text { months. }\end{array}$ \\
\hline Pre-operation & Not recommended & $\begin{array}{l}\text { Cardiopulmonary surgery, if } \\
\text { clinical examination suggests } \\
\text { that malignancy or pulmonary } \\
\text { tuberculosis is a strong } \\
\text { possibility; when the incidence } \\
\text { of pulmonary tuberculosis in the } \\
\text { patient's ethnic group may be } \\
\text { more than } 1: 1000 \text { and when } \\
\text { chest } x \text {-ray has not been } \\
\text { performed in the last six } \\
\text { months. }\end{array}$ \\
\hline $\begin{array}{l}\text { On admission to hospital, } \\
\text { during pregnancy, } \\
\text { pre-employment }\end{array}$ & Not recommended & $\begin{array}{l}\text { Guidelines may be waived at the } \\
\text { discretion of the clinician e.g. if } \\
\text { clinical examination suggests } \\
\text { that malignancy or pulmonary } \\
\text { tuberculosis is a strong } \\
\text { possibility. }\end{array}$ \\
\hline
\end{tabular}

Chest $x$-roys occount for $33 \%$ of all examinotions

Page from Royal College of Radiologists' booklet, showing guidance for selecting patients for $\mathrm{x}$ ray examination centre and in every specialty after guidelines were instituted. The major part of this reduction was achieved by some of the firms whose initial practice did not meet "high referral" criteria. Important variations in compliance with agreed standards of good practice were observed.

Conclusions-The study offers strong experimental evidence to support a recent suggestion that at least a fifth of radiological examinations carried out in NHS hospitals are clinically unhelpful. The problem of how to assure compliance with agreed standards of practice needs to be resolved. Until this happens medical audit alone is unlikely to translate good practice into common practice.

\section{Introduction}

In 1976 the Royal College of Radiologists established a working party on the more effective use of diagnostic radiology. At its first meeting it concluded that a series of advisory guidelines should be compiled to help hospital doctors and general practitioners make the best use of their local $x$ ray department. Unable to find sufficient information on which to base these guidelines, the working party embarked on a series of multicentre studies to examine the clinical effectiveness of some of the most commonly used diagnostic radiological procedures.

By 1986 the working party had gathered sufficient information to compile, in booklet form, an extensive range of guidelines covering the most frequently used $x$ ray examinations.' This compilation drew on the results of the working party's multicentre and other studies,,$^{2-10}$ a review of the relevant scientific literature, and the expertise of many clinical colleagues who had been involved in the studies over the period 1976 to 1986. In all, some 150 consultant radiologists and 800 NHS consultants representing 14 specialties from 25 different centres in the United Kingdom contributed.

The working party thought that the booklet would be effective only if its use was also supported by monitoring and review of referral practice by com- $\sigma$ mittees of local clinicians. Between 1987 and 1990 the $D$ working party evaluated this approach in six centres in England and Wales. This study was carried out in two $N$ parts: $x$ ray referral practice was monitored for $12 \mathrm{~N}$ months in each centre ${ }^{11}$; then the responses of the $\sigma$ centres to the implementation of guidelines, monitoring, and peer review, and their effect on subsequent referral practice, were observed. These findings are reported in the present paper.

\section{Methods}

ROYAL COLLEGE OF RADIOLOGISTS' GUIDELINES BOOKLET

The booklet presents some 70 guidelines covering seven categories of $x$ ray examination-chest, limbs and joints, spine, abdomen, barium investigations, skull, and excretion urography - that comprise about $90 \%$ of all $x$ ray examinations currently undertaken in the NHS

The figure shows a page from the booklet. Guidance for selecting patients for a particular examination is 
laid out in three columns. The first lists the more common circumstances in which the examination is currently used. Most entries under this heading are clinical and refer to the patient's presenting symptoms and signs. Non-clinical circumstances - for example, pre-employment screening, are listed next. The second column contains the guideline which generally governs the use of the examination in the given circumstance. The third column lists any better known and generally agreed exceptions to the guideline.

The guidelines aim to encourage more appropriate use of diagnostic radiology and so reduce the use of clinically unhelpful $x$ ray examinations. ${ }^{12}$ The working party, and others, have reported dramatic reductions in referral rates following compliance with guidelines for $x$ ray of the chest, ${ }^{13-15}$ skull,,${ }^{16-20}$ lumbar spine, ${ }^{21}$ and injured extremities ${ }^{22}$ without prejudice to patient care. Recent work also suggests that compliance with the guidelines could lead to substantial reductions in out of hours referrals, ${ }^{72324}$ and the use of hospital radiology services by general practitioners. ${ }^{25}$

\section{COMPUTERISED MONITORING OF $X$ RAY REFERRAL PRACTICE}

The study required each centre to have a computerised data collection system to monitor routinely the number of referrals for $x$ ray examinations per 100 inpatient discharges, deaths, and day cases and per 100 new outpatient attendances. In this paper the audit is confined to inpatient and outpatient referrals by hospital firms. The influence of guidelines on the referral practice of general practitioners and of doctors working in accident and emergency units will be reported separately

Table I shows the essential characteristics of the study population. It consisted of 314663 inpatient discharges, deaths, and day cases and 1706781 outpatient attendances under the care of 722 consultants from 25 clinical specialties in three teaching and three non-teaching centres (two in Wales, and one in each of the Northern, South West Thames, Trent, and Wessex regions). The data in each centre were collected over a continuous period of 21-24 months sometime between January 1987 and December 1990 and included a period of 9-12 months in each centre where baseline referral data were collected before the guidelines were introduced. The results of this baseline audit are published elsewhere."

Individual firms were included in the audit if they met the following criteria: for inpatient referrals, a minimum workload of $100 x$ ray examination referrals and 250 inpatient discharges, deaths, and day cases (150 in geriatrics) in the year of the study; for outpatient referrals, a minimum of $100 x$ ray examination referrals and a minimum of 500 total or 100 new attenders in the year of the study. Data from a particular centre were not included if none of the firms in a specialty or subspecialty in that centre met the above inclusion criteria; if there were no inpatient beds or outpatient facilities in that specialty; or if there was a concern about the accuracy of the data.

\section{PEER REVIEW}

A radiology review committee was established in each centre. This was chaired by the local coordinator and the major specialties were always represented. Initial tasks were to endorse the guidelines as hospital policy; oversee the distribution of the booklet to clinical users and particularly to junior medical staff; and, if necessary, suggest modifications to match local circumstances so that a feeling of local ownership could be engendered. A later task concerned compliance with guidelines and how this might be monitored and encouraged, particularly as past experience had shown that passive feedback of utilisation data to individual consultants had not, on its own, been successful in sustaining more selective use of clinical investigations. ${ }^{26-29}$

Local committee meetings were always attended by an external consultant from the study headquarters who provided data from other centres for comparison and advice on the interpretation of local data. Initially all committees expressed reservations about intervening if the monitoring identified certain firms whose practice was at variance with that of colleagues in the same specialty, but attitudes changed as the project progressed and as the wide variations in practice came to light.

Firms who consistently showed substantially higher examination referral rates than others in the same specialty were identified as possible targets for "intervention" by the radiology review committees. Intervention was considered only when a firm met one of the following criteria: referral rates that were twice the average local specialty rate for at least three consecutive quarters; initially high and increased steadily over the period of the study; or three times the rates observed for the specialty in other centres.

Four committees agreed to intervene. A fifth agreed in principle but not on how the intervention might be carried out once a "high referral" firm had been identified. A sixth was not prepared to intervene or to apply the criteria and did not wish to go beyond closed monitoring by the committee. In this hospital the committee disbanded as soon as the research project was completed.

Intervention ranged from an informal discussion between a member of the committee and a colleague to a formal presentation to all medical staff of a firm or specialty by one or two members of the committee. For example, in rheumatology in one centre where wide variation was observed, all consultants were invited to review the results of their referral practice. The referral rate of the individual firms, together with those of firms in the same specialty from other centres, were presented in coded form. Only at the end of the discussion was the identity of the local firms revealed. Before the code was broken the individual consultants were quite unable to decide whether they were among the high or low users despite the fact that they all agreed with the guidelines. One consultant who was out of step and whose referral practice was considerably higher than that of his colleagues agreed to review his practice in some detail.

\section{Results}

Overall, inpatient referrals were reduced by $7 \cdot 7 \%$ and outpatient referrals by $8 \cdot 9 \%$. Table II presents referral rates before and after implementation of the guidelines by type of $x$ ray examination. All outpatient data from one centre were excluded because requests generated by consultants from clinics based at that centre could not be distinguished from those generated by the same consultants at satellite clinics. Orthopaedic outpatient referrals from another centre were also

185765 excluded because of contamination of outpatient attendances by those from the accident and emergency

722

314663

402943 
department. Reductions occurred in all seven categories of inpatient $x$ ray examination and in six of seven categories of outpatient examination. Table III shows changes in the referral rates of eight specialties (232 firms) that together generated $73 \%$ of all inpatient and outpatient referrals recorded in the study. All outpatient data from one centre were excluded because requests generated by consultants from clinics based at that centre could not be distinguished from those generated by the same consultants at satellite clinics. Orthopaedic outpatient referrals from another centre were also excluded because of contamination of outpatient attendances by those from the accident and emergency department. Substantial reductions in inpatient and outpatient referrals were recorded in the specialties of general medicine; obstetrics and gynaecology; and ear, nose, and throat medicine. Outpatient referrals in general surgery and paediatrics and orthopaedics were substantially reduced. Large reductions were recorded by individual centres and in every specialty. No constant relation with initial level of referral was observed.

Analysis of chest $x$ ray referral rates from ophthalmology in the three teaching centres illustrates how variation in compliance was as great as the variation in referral practice reported earlier." In this specialty

TABLE II - Changes in $\mathrm{x}$ ray referral rates by type of examination and by source of referral

\begin{tabular}{|c|c|c|c|c|c|c|}
\hline \multirow{2}{*}{$\begin{array}{l}x \text { Ray } \\
\text { examination }\end{array}$} & \multirow{2}{*}{$\begin{array}{c}\text { Total No } \\
\text { of } x \text { ray } \\
\text { examinations }\end{array}$} & \multicolumn{3}{|c|}{ Referral rate } & \multirow{2}{*}{$\begin{array}{l}\text { No of eligible } \\
\text { centres with } \\
\text { reductions } \\
\text { in year } 2\end{array}$} & \multirow{2}{*}{$\begin{array}{l}\text { Largest \% } \\
\text { reduction by } \\
\text { single centre }\end{array}$} \\
\hline & & Year 1 & Year 2 & Reduction $(\%)$ & & \\
\hline \multicolumn{7}{|l|}{ Chest: } \\
\hline Inpatients & 143747 & $45 \cdot 2$ & $42 \cdot 4$ & $6 \cdot 2$ & $5 / 6$ & $13 \cdot 6$ \\
\hline Outpatients & 54296 & $14 \cdot 8$ & $12 \cdot 8$ & $13 \cdot 5$ & $3 / 5$ & $24 \cdot 9$ \\
\hline \multicolumn{7}{|l|}{ Skull: } \\
\hline Inpatients & 3876 & $1 \cdot 4$ & $1 \cdot 0$ & $28 \cdot 6$ & $6 / 6$ & $44 \cdot 1$ \\
\hline Outpatients & 10230 & $2 \cdot 8$ & $2 \cdot 2$ & $21 \cdot 4$ & $4 / 5$ & $39 \cdot 1$ \\
\hline \multicolumn{7}{|l|}{ Spine: } \\
\hline Inpatients & 8692 & $2 \cdot 9$ & $2 \cdot 6$ & $10 \cdot 3$ & $5 / 6$ & $25 \cdot 7$ \\
\hline Outpatients & 21260 & $5 \cdot 3$ & $4 \cdot 6$ & $13 \cdot 2$ & $4 / 5$ & $31 \cdot 6$ \\
\hline \multicolumn{7}{|l|}{ Abdomen: } \\
\hline Inpatients & 19506 & $6 \cdot 6$ & $6 \cdot 2$ & $6 \cdot 0$ & $3 / 6$ & $18 \cdot 8$ \\
\hline Outpatients & 5513 & $1 \cdot 2$ & $1 \cdot 3$ & $8 \cdot 3 \dagger$ & $2 / 5$ & $15 \cdot 0$ \\
\hline \multicolumn{7}{|l|}{ Barium: } \\
\hline Inpatients & 6700 & $2 \cdot 2$ & $2 \cdot 1$ & $4 \cdot 5$ & $2 / 6$ & $17 \cdot 5$ \\
\hline Outpatients & 15176 & 3.9 & 3.6 & $7 \cdot 7$ & $4 / 5$ & $29 \cdot 7$ \\
\hline \multicolumn{7}{|c|}{ Excretion urography: } \\
\hline Inpatients & 3198 & $1 \cdot 1$ & $1 \cdot 0$ & $9 \cdot 1$ & $4 / 6$ & $28 \cdot 3$ \\
\hline Outpatients & 7120 & 1.8 & 1.5 & $16 \cdot 7$ & $4 / 5$ & $24 \cdot 2$ \\
\hline \multicolumn{7}{|c|}{ Limbs and joints: } \\
\hline Inpatients & 29396 & $10 \cdot 9$ & $10 \cdot 4$ & $4 \cdot 6$ & $5 / 6$ & $21 \cdot 3$ \\
\hline Outpatients & 74233 & $16 \cdot 5$ & $15 \cdot 8$ & $4 \cdot 2$ & $3 / 5$ & $19 \cdot 2$ \\
\hline
\end{tabular}

* Per 100 inpatient discharges, deaths, or day cases or per 100 new outpatient attenders for all hospitals combined. tIncrease.

TABLE III -Changes in $\mathrm{x}$ ray referral rates by specialty and by source of referral

\begin{tabular}{|c|c|c|c|c|c|c|}
\hline \multirow[b]{2}{*}{ Specialty } & \multirow{2}{*}{$\begin{array}{c}\text { Total No } \\
\text { of } x \text { ray } \\
\text { examinations }\end{array}$} & \multicolumn{3}{|c|}{ Referral rate $\nmid$} & \multirow{2}{*}{$\begin{array}{l}\text { No of eligible } \\
\text { centres with } \\
\text { reductions } \\
\text { in year } 2\end{array}$} & \multirow{2}{*}{$\begin{array}{l}\text { Largest \% } \\
\text { reduction by } \\
\text { single centre }\end{array}$} \\
\hline & & Year 1 & Year 2 & Reduction $(\%)$ & & \\
\hline \multicolumn{7}{|l|}{ Medicine: } \\
\hline Inpatients & 47811 & $91 \cdot 4$ & $80 \cdot 1$ & $12 \cdot 4$ & $6 / 6$ & $18 \cdot 2$ \\
\hline Outpatients & 31406 & $107 \cdot 8$ & $91 \cdot 0$ & $15 \cdot 6$ & $3 / 5$ & $31 \cdot 0$ \\
\hline \multicolumn{7}{|l|}{ Surgery: } \\
\hline Inpatients & 40658 & $62 \cdot 4$ & $59 \cdot 1$ & $5 \cdot 3$ & $5 / 6$ & $16 \cdot 9$ \\
\hline Outpatients & 19794 & $32 \cdot 3$ & $27 \cdot 9$ & $13 \cdot 6$ & $4 / 5$ & $47 \cdot 0$ \\
\hline \multicolumn{7}{|l|}{ Paediatrics: } \\
\hline Inpatients & 19046 & $56 \cdot 0$ & $52 \cdot 3$ & $6 \cdot 6$ & $3 / 6$ & $33 \cdot 8$ \\
\hline Outpatients & 9210 & $64 \cdot 6$ & $56 \cdot 1$ & $13 \cdot 2$ & $4 / 5$ & $42 \cdot 9$ \\
\hline \multicolumn{7}{|l|}{ Geriatrics: } \\
\hline Inpatients & 10926 & $134 \cdot 3$ & $126 \cdot 2$ & $6 \cdot 0$ & $3 / 4$ & $22 \cdot 3$ \\
\hline \multicolumn{7}{|c|}{ Obstetrics and gynaecology: } \\
\hline Inpatients & 3072 & $7 \cdot 4$ & $4 \cdot 9$ & $33 \cdot 8$ & $4 / 4$ & $46 \cdot 1$ \\
\hline Outpatients & 1758 & $3 \cdot 8$ & $2 \cdot 2$ & $42 \cdot 1$ & $4 / 4$ & $80 \cdot 5$ \\
\hline \multicolumn{7}{|l|}{ Orthopaedics: } \\
\hline Inpatients & 24556 & $125 \cdot 0$ & $124 \cdot 9$ & $0 \cdot 0$ & $3 / 6$ & $21 \cdot 9$ \\
\hline Outpatients & 58473 & $125 \cdot 3$ & $104 \cdot 6$ & $16 \cdot 5$ & $3 / 4$ & $30 \cdot 2$ \\
\hline \multicolumn{7}{|c|}{ Ear, nose, and throat: } \\
\hline Inpatients & 3274 & $18 \cdot 8$ & $14 \cdot 0$ & $25 \cdot 5$ & $4 / 5$ & $41 \cdot 4$ \\
\hline Outpatients & 4679 & 11.5 & $10 \cdot 3$ & $10 \cdot 4$ & $4 / 4$ & $18 \cdot 8$ \\
\hline \multicolumn{7}{|l|}{ Rheumatology: } \\
\hline Outpatients & 19469 & $186 \cdot 0$ & $166 \cdot 9$ & $10 \cdot 3$ & $3 / 4$ & $21 \cdot 2$ \\
\hline
\end{tabular}

${ }^{\star}$ Chest, skull, spine, abdomen, barium, excretion urography, limbs and joints.

+Per 100 inpatient discharges, deaths or day cases or per 100 new outpatient attenders. tPer 100 in most requests for inpatient chest $x$ ray are made preoperatively, a clinical circumstance that is considered explicitly in the guideline booklet (figure). In centre $A$ the inpatient chest $x$ ray referral rate rose from 18 per 100 inpatient discharges, deaths, and day cases in year 1 to 21 in year 2 . In centre B it fell from 6 to 3 , and in centre $C$ from 61 to 12 - changes in referral rates of $+11 \%,-40 \%$, and $-80 \%$. No clinical explanation could be identified to account for this variation in response.

Of the firms represented in table III, 174 met the workload criteria, and of those $31(18 \%)$ also met the high referral criteria and were drawn to the attention of the committees by the external consultant. Only eight "interventions" were actually carried out. The outcome of these was a fall in referral rate in five, no change in two, and the identification of a clinical explanation to account for apparently high referral by one firm

\section{Discussion}

There is abundant evidence from the present study that the introduction of guidelines, monitoring, and peer review was followed by appreciable and often dramatic reductions in referral for individual $x$ ray examinations from a substantial number of firms in every centre and in every specialty. Most of this reduction was produced by firms whose preguideline practice did not meet our "high referral" criteria. This suggests that opportunities for further substantial reductions remain.

Even with voluntary adoption of the guidelines, voluntary peer review, and limited assurance of compliance, overall reductions in inpatient and outpatient referrals of $7.7 \%$ and $8.9 \%$, respectively, were recorded. This represents a potential saving of $£ 180000$ a year in the study hospitals alone and does not include any savings that might be attributed to changes in referral practice not dealt with in this paper, such as referrals from accident and emergency units and from general practitioners. If the guidelines became a required standard of good practice for the NHS, if formal peer review became a necessary part of hospital practice, and if the assurance of compliance was more rigorously pursued the evidence suggests that reductions in excess of $20 \%$ would be achieved. In financial terms alone this would represent annual savings to the NHS of some $£ 50-60 \mathrm{~m}$, approximately $£ 250000$ for each health authority. We know of no reason why the findings should apply only to diagnostic radiological services. There is a strong likelihood that the substantial overuse we have shown applies also to other major sectors of hospital care in the NHS.

Doctors were prepared to accept as hospital policy standards of clinical practice set by peers from elsewhere, and were also agreeable to the monitoring and review of their practice with respect to these standards by committees of local peers and colleagues, many of whom were from different specialties. Committees experienced little difficulty in agreeing which firms met the criteria for persistent high referral, but there was considerable disagreement about the desirability of formal intervention. Procedures to encourage compliance were therefore not implemented in 23 out of 31 $(74 \%)$ instances of apparently persistent high referral. In the eight instances where they were implemented, a satisfactory outcome was achieved in six. The findings of this study have important implications for the audit studies presently being conducted across the broad front of medical practice.

The study offers strong experimental evidence to support a recent suggestion that at least $20 \%$ of radiological examinations carried out in NHS hospitals are clinically unhelpful. Introducing the guideline 
booklet on its own can be expected to have, at best, only a transient effect on this. ${ }^{20030-32}$ Yet pressures to consider only the guidelines and their further refinement, and to ignore monitoring and peer review, continue to be enormous. The problem of how to assure compliance with an agreed standard of practice needs to be resolved. Until this happens medical audit alone is unlikely to translate good practice into common practice.

We thank all those concerned with the study in the participating centres, particularly clinical and management colleagues who served on local radiology review committees, and the Department of Health and the King's Fund for financial support.

1 Royal College of Radiologists. Making the best use of a department of radiology. Guidelines for doctors. London: RCR, 1989.

2 Royal College of Radiologists Working Party. Pre-operative chest radiology. Lancet 1979;ii:82-6.

3 Royal College of Radiologists Working Party. A study of the utilisation of skull radiography in nine accident and emergency units in the UK. Lance 1980;ii: 1234-6.

4 Royal College of Radiologists Working Party. Costs and benefits of skul radiology for head injury. Lancet 1981;ii:791-5.

5 Royal College of Radiologists Working Party. Patient selection for skul radiology in uncomplicated head injury. Lancet 1983;i:115-8.

6 Royal College of Radiologists Working Party. Radiography of injured arm and legs in eight accident and emergency units in England and Wales. $B M \mathcal{J}$ and legs in eight accic $1985: 291: 1325-8$.

7 Charny MC, Roberts GM, Roberts CJ. Out of hours radiology, a suitable case for audit. Br J Radiol 1987;60:553-6.

8 Hayward MWJ, Hayward C, Ennis WP, Roberts CJ. A pilot evaluation of radiography of the acute abdomen. Clin Radiol 1984;35:289-9

9 Hayward MWJ, Lyons K, Ennis WP, Rees J. Radiography of the paranasa sinuses - one or three views? Clin Radiol 1990;41:165-9.

10 Roberts $\mathrm{CJ}$. Towards the more effective use of diagnostic radiology: a review of the work of the Royal College of Radiologists Working Party on the mor effective use of diagnostic radiology, 1976-1986. Clin Radiol 1988;39:3-6.

Copies of the guidelines referred to in this article can be obtained from:

The Guidelines Secretary, Royal College of

Radiologists, 38 Portland

Place, London W1N 3DG. referral for radiological investigation in England and Wales. BMJ 1991; 303:809-12.

12 Royal College of Radiologists and National Radiological Protection Board. Patient dose reduction in diagnostic radiology. London: $\mathrm{HMSO}, 1990$.

13 Roberts CJ, Fowkes FGR, Mitchell M. Possible impact of audit on chest $x$-ray requests from surgical wards. Lancet 1983;ii:446-8.
11 Royal College of Radiologists Working Party. A multicentre audit of hospital
14 Fowkes FGR. Strategies for changing the use of diagnostic radiology. London: King's Fund, 1985. (Project paper No 57.)

15 Thompson RS, Kairz HL, Gold RA. Changes in physicians' behaviour and cost savings associated with organisational recommendations on the use of "routine" chest x-rays and multi-channel blood tests. Prev Med 1983;12: 385-96.

16 Phillips LA. Comparative evaluation of the effect of a high yield criteria list upon skull radiography. fournal of the American College of Emergency Physicians 1979;8:1069-76.

17 Cummins RO, Logerfa JP, Inui TS, Weiss NS. High yield referral criteria for post-traumatic skull roentgenology. FAMA 1980;244:673-6.

18 Cordon IW. Skull roentgenography for patients with head trauma: the use of high yield criteria. Can Med Assoc f 1981;124:584-9.

19 Fowkes FGR, Evans RC, Williams LA, Gehlbach SH, Cook BRB, Roberts CJ. Implementation of guidelines for the use of skull radiographs in patients with head injuries. Lancet 1984:

20 Clarke JA. Adams JE. The application of clinical guidelines for skull radiography in the accident and emergency department. Theory and practice Clin Radiol 1990;41:152-5.

21 Baker SR, Rabin A, Lantos G, Gallagher EJ. The effect of testricting the indications for lumbosacral spine radiography in patients with acute back symptoms. $A 7 R$ 1987;149:531-8.

22 Brand DA, Frazer WH, Kohlepp WC, Shea KM, Hoefer EM, Ecker MD, $e t$ al. A protocol for selecting patients with injured extremities who need $\mathrm{x}$-rays. $N$ Engl I Med 1982;306:333-9.

23 Charny MC, Roberts GM, Beck P, Webster DJ, Roberts CJ. How good are casenotes in the audit of radiological investigations. Clin Radiol 1990;42: $118-21$

24 Clarke JA, Adams JE. A critical appraisal of "out-of-hours" radiography in a major teaching hospital. Brf Radiol 1988;61:1100-5.

25 Vos Meiring PD, Wells IP. The effect of radiology guidelines for general practitioners in Plymouth. Clin Radiol 1990;42:327-9.

26 Pozen MW, Gloger H. The impact on house officers of educational and administrative interventions in an outpatient department. Soc Sci Med 1976;10:491-5.

27 Rhyne RL, Gehlbach SH. Effects of an educational feedback strategy on physician utilisation of thyroid function panels. I Fam Pract 1979;8:1003-7. 28 Eisenberg JM, Williams SV, Garner L, Viale R, Smits H. Computer based audit to detect and correct over-utilisation of laboratory tests. Med Care

29 Mitchell MW, Fowkes FGR. Audit reviewed. Does feedback on performance change clinical behaviour? $\mathcal{F} R$ Coll Physicians 1985; 19:251-4.

30 Gosecoff J, Kanouse DE, Rogers WH, McCloskey L, Winslow CM, Brook RH. Effects of the National Institute of Health Consensus Development Program on physician practice. FAMA 1987;258:2708-13.

31 Lomas J, Anderson GM, Domnick-Pierre K, Vayda E, Enkin MW, Hannah WJ. Do practice guidelines guide practice? The effect of a consensus statement on the practice of physicians. $N$ Engl f Med 1989;321: 1306-11.

32 Lomas J, Elkin M, Anderson GA, Hannah WJ, Vayda E, Singer J. Opinion leaders versus audit and feedback to implement practice guidelines: delivery after previous cesarean section. JAMA 1991;265:2202-7.

(Accepted 20 December 1991)
Unit of Clinical

Epidemiology, University of Oxford, Oxford

OX3 7LF

Henriet Nienhuis, MSC, epidemiologist

Michael Goldacre, FFPHM director

Valerie Seagroatt, MSC, statistician

Leicester Gill, MSC, chief

computer scientist

\section{Department of Public}

Health and Primary Care,

Radcliffe Infirmary,

University of Oxford,

Oxford OX2 6HE

Martin Vessey, FRS, professor

Correspondence to:

Dr Goldacre.

$B M F$ 1992;304:743-6

\title{
Incidence of disease after vasectomy: a record linkage retrospective cohort study
}

\author{
Henriet Nienhuis, Michael Goldacre, Valerie Seagroatt, Leicester Gill, Martin Vessey
}

\section{Abstract}

Objective-To determine whether vasectomy is associated with an increased risk of several diseases, and in particular testicular cancer, after operation.

Design-Retrospective cohort study using linked medical record abstracts.

Setting-Six health districts in Oxford region.

Subjects -13246 men aged 25-49 years who had undergone vasectomy between 1970 and 1986, and 22196 comparison subjects who had been admitted during the same period for one of three specified elective operations, appendicitis, or injuries.

Main outcome measures-Hospital admission and death after vasectomy or comparison event.

Results - The mean durations of follow up were 6.6 years for men with a vasectomy and 7.5 years for men with a comparison condition. The relative risk of cancer of the testis in the vasectomy cohort ( 4 cases) compared with that in the other cohorts $(17$ cases) was $0.46(95 \%$ confidence interval 0.1 to 1.4$)$, that of cancer of the prostate ( $1 v 5$ cases) 0.44 ( 0.1 to 4.0), and that of myocardial infarction (97 $v 226$ cases) $1.00(0.8$ to 1.3$)$. There was no evidence of an increase associated with vasectomy in the incidence of a range of other diseases.

Conclusion-Vasectomy was not associated with an increased risk of testicular cancer or the other diseases studied. With respect to prostatic cancer, while we found no cause for concern, longer periods of observation on large numbers of men are required.

\section{Introduction}

Vasectomy is now a common method of permanent birth control. Though widely considered to have no adverse long term effects on health, doubts have occasionally been raised about its safety. These include concerns about the functional importance, if any, of the autoimmune sperm antibody response that commonly follows vasectomy ${ }^{12}$ and the possibility of long term effects of the operation on the cardiovascular $^{3-10}$ and genitourinary systems. Also, there is current interest in the hypothesis that vasectomy might predispose men to cancers of the testis and prostate..$^{11-16}$ We report a medical record linkage study to identify the subsequent occurrence of these cancers and severa other diseases after vasectomy.

\section{Methods}

We used data from the Oxford record linkage study, which includes brief abstracts of records of hospital 